


\title{
Un vértice para la construcción de sentidos: Estudios culturales, de género y literarios
}

\section{A meeting space for the building of meaning: Cultural Studies on Gender and Literature}

\author{
Ana Alejandra Robles Ruiz \\ Centro de Estudios Superiores de México y Centroamérica \\ (CESMECA), México \\ ale_robbles@hotmail.com \\ Patricia del Carmen Guerrero de la Llata \\ Universidad de Sonora, México \\ pguerrero@correom.uson.mx
}

Resumen: El objetivo de este artículo es definir qué son los estudios culturales, de género y literarios. Reflexionar acerca de la relación que hay entre ellos. Debatir cómo es posible el hecho de que puedan intersecarse éstos e intentar explicar el funcionamiento teórico y metodológico de dichas interdisciplinas. Asimismo, este trabajo ofrece un panorama general con respecto a la situación actual de los estudios de género y los estudios literarios con esta perspectiva en México: ¿qué es lo que se está haciendo?, ¿cómo?, ¿en dónde?

Palabras clave: interdisciplina, conceptos viajeros, estudios literarios, feminismos, humanidades.

Abstract: The objective of this article is to define what cultural, gender and literary studies are. Reflect on the relationship between them. Discuss how it is possible that they intersect. And try to explain the theor- 
etical and methodological functioning of these interdisciplines. Likewise, this work offers a general panorama with respect to the current situation of gender studies and literary studies with this perspective in Mexico: what is being done? how? where?

Keywords: Interdiscipline, Travelling Concepts, Literary Studies, Feminisms, Humanities.

Recibido: 25 de marzo de 2018

Aceptado: 10 de mayo de 2018 http://dx.doi.org/10.15174/rv.v0i24.397

$\mathrm{Z}^{\mathrm{l}}$ presente texto desarrolla una serie de reflexiones en torno a los estudios culturales y su relación con los estudios literarios y los estudios de género; con el objetivo de repensar, por un lado, cuál es el eje que ha permitido que los estudios culturales -en especial los estudios de género- se hayan intersecado con los estudios literarios y, por otro, observar si es conveniente o no la práctica de la interdisciplina entre estos tres campos del saber.

Los estudios culturales son un área del conocimiento que utiliza la interdisciplina para el estudio de las formas de producción y difusión de significados en una sociedad. Estudia sobre todo los discursos reguladores de prácticas sociales y el papel de los juegos de poder en las actividades cotidianas que dan sentido a la realidad social y remiten a cuestiones de ideología, de nacionalidad, de etnia, de género, de clase social. Los estudios culturales surgen ante la necesidad de romper los límites que las disciplinas imponen por sí mismas y se han convertido en un campo diverso de estudios que alterna diferentes perspectivas y métodos.

Stuart Hall, que junto a Richard Hoggart, es uno de los precursores de los estudios culturales, habla precisamente de que estos estudios surgen en Inglaterra durante la segunda mitad del siglo 
$\mathrm{XX}$, como resultado de una crisis en las humanidades. ${ }^{1}$ Crisis en el sentido de que es cuestionable en ese entonces la auto-representación de las humanidades como un ejercicio integral e integrador (11-12). Es decir, en ese momento la necesidad más apremiante era que las humanidades tuvieran un protagonismo crítico en el momento histórico y en la situación cultural en la que se ubicaban, sin embargo estas disciplinas ignoraban su realidad y su presente.

De alguna manera, esto nos lleva a pensar en la situación actual de la producción del conocimiento en general. Vemos que hoy en día, con la acumulación del saber cada vez más rápida y urgente, es necesario ampliar los campos del conocimiento que están divididos y especializados a tal grado que se aíslan y producen conocimientos muy específicos. Así, cuando se requiere trabajar con algún tema, los académicos nos vemos insatisfechos por la imposibilidad de hacer análisis y críticas más pertinentes debido a las limitaciones disciplinares. Es aquí en donde los estudios culturales pretenden completar vacíos analíticos y epistemológicos, proponiendo partir de estudios interdisciplinarios. Como bien afirma Hall, los estudios culturales siempre han existido, han sabido adaptarse y se han desarrollado a partir de una matriz diferente de estudios interdisciplinarios. ${ }^{2}$ No podemos afirmar que no se hacen estudios culturales desde la interdisciplina, porque hay presencia de las interconexiones aun cuando no se hagan bajo el sello de los estudios culturales; pero lo que sí se puede afirmar es que en numerosas ocasiones se presentan inconvenientes al estudiar ciertos temas o emplear metodologías no tradicionales dentro de las disci-

${ }^{1}$ A la fecha, es muy difícil consensuar qué son las humanidades. Sin embargo, según el artículo de Hall que aquí se cita, sabemos que por lo menos él distingue entre humanidades y ciencias sociales.

2 "Cultural studies was then, and has been ever since, an adaptation to its terrain; it has been a conjunctural practice. It has always developed from a different matrix of interdisciplinary studies" (Hall, 1990: 11). 
plinas, debido a las demarcaciones que las áreas del conocimiento imponen.

Pero, ¿cómo funcionan los estudios culturales? Grossber, insiste en "Stuart Hall sobre raza y racismo: Estudios culturales y la práctica del contextualismo", que para Hall, el nivel de análisis y teorización adecuado en los estudios culturales es en el plano de las coyunturas o los contextos específicos (Grossber, 2006: 48). ${ }^{3}$ Es decir que los estudios culturales se encargan de analizar y teorizar acerca de procesos, relaciones y prácticas exclusivamente ubicadas en un momento o contexto particular. El autor explica que los estudios culturales pretenden entender lo general incluso en su contexto (54), aunque esto tampoco quiere decir que dichos estudios tengan la pretensión de singularizarlo todo (54). En otras palabras, los estudios culturales buscan evitar reproducir universalismos, más bien proponen prácticas que sean capaces de admitir la complejidad y evitar reduccionismos (47).

No es fácil entender, en los términos acostumbrados de las disciplinas, el mecanismo que utilizan los estudios culturales, mucho menos cuando éstos se presentan a sí mismos como una antidisciplina. Sin embargo, se debe tener presente, que aunque los estudios culturales no se sustentan en una teoría y en una metodología específicas, siempre se rigen por fundamentos disciplinares; además es importante reconocer que no son, o no deberían ser por lo menos, estudios arbitrarios, caprichosos y faltos de precisión. Su singularidad radica en que en vez de partir de una disciplina utiliza varias si su objeto de estudio así lo requiere. De ahí que sean interdisciplinarios, y por lo tanto se conciban como antidisciplina (en singular).

${ }^{3}$ Grossberg define coyuntura como: "la descripción de una formación social como fracturada y conflictual, a lo largo de múltiples ejes, planos y escalas, en una búsqueda constante de equilibrios provisorios o estabilidades estructurales mediante una variedad de prácticas y procesos de lucha y negociación” (2006: 56). 
Para darnos una idea más concreta de cómo se puede hacer un estudio interdisciplinario, nos parece apropiado traer a colación a Mieke Bal. En su muy interesante texto "Conceptos viajeros en las humanidades", Bal sostiene que los conceptos no están fijos, sino que viajan entre disciplinas, entre estudiosos, entre períodos históricos y comunidades académicas (2006: 31). Esto quiere decir que un concepto que fue originado en la sociología - por mencionar una disciplina- bien puede utilizarse, debido a estos viajes, en la literatura, en la historia o en cualquier otro campo del saber. ${ }^{4}$ ¿Pero

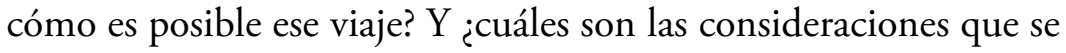
deben tener en cuenta al momento de hacerlo? Bien, la estudiosa insiste en que un concepto no es sólo una representación abstracta de un objeto. Ella opina que los conceptos necesitan ser claros, explícitos y definidos (2006: 28). Dice que los conceptos son flexibles, que tienen la capacidad de mutar, que una vez delimitado un concepto puede formar parte de una metodología que no sea rígida y que por lo tanto es importante poner a los conceptos en discusión entre disciplinas (32-34). Sabemos que hay significados fijos y universales que vienen de tradiciones académicas y epistémicas; sin embargo, como sugiere Bal, es conveniente examinar los conceptos en sí mismos, valorar sus posibilidades y delimitarlos de acuerdo con los objetos que pretenden explicarse (47). De esta manera se tiene la oportunidad de rastrear la trasformación de los conceptos en el tiempo y en las disciplinas que les dieron origen y buscar una manera óptima de reformularlos, en función de una mayor o menor cercanía con el objeto de estudio con el cual se esté trabajando.

${ }^{4}$ Tanto Mieke Bal en "Conceptos viajeros", como Rosi Braidotti en Sujetos nómades, mencionan el trabajo de Isabelle Stengers: D'unescience à l'autre. Des conceptsnomades (1987), en el que se refiere a conceptos nómadas, para hablar de que es posible compartir conceptos no sólo entre ciencias "blandas", sino también entre éstas y las ciencias "duras". 
Otro punto que consideramos valioso destacar del viaje de conceptos es que éste sólo es posible en la interdisciplina. Ni la multidisciplina, ni la transdisciplina ofrecen la oportunidad de que se realice. El viaje de conceptos implica que un concepto viaje de una disciplina a otra y que regrese a la primera, luego de una negociación y re-evaluación del mismo para ser utilizado en objetos particulares de estudio; la transdisciplina presupone el viaje de un concepto de un lado al otro, pero sin transformarse; la multidisciplina implica someter a ambos campos de saber una herramienta de análisis común, lo que le restaría especificidad (Bal, 2006: 51). Así, los estudios culturales, como interdisciplina, se aseguran de apoyarse en conceptos de distintas disciplinas, pero siempre responsabilizándose de hacer una negociación, una transformación y una revaloración de los mismos en una interacción directa con los objetos de estudio y la coyuntura.

En cuanto a las posibles líneas que pueden seguir los estudios culturales, se pueden mencionar la raza, la identidad, la migración, la comunicación, la colonialización, el poscolonialismo, los estudios de la ciencia, la tecnocultura, el orientalismo, el multiculturalismo, el género, entre otras. Cada una de estas líneas tiene que ver con variedades de formas y prácticas culturales que abrazan en su interior discursos reguladores de prácticas y articulaciones de poder. Y si bien estimamos que vale la pena reflexionar sobre todas las líneas ya mencionadas, nos limitaremos a hablar, como se dijo al principio del artículo, de la línea del género; de cómo funciona y de cómo es que, en calidad de estudio cultural, es posible que interactúe con los estudios literarios.

De alguna manera, se puede decir que los estudios de género nacen en los setenta con el feminismo. ${ }^{5}$ El feminismo académico

${ }^{5}$ Antes de los setenta ya se había hablado de género: Margaret Mead, Linton, Murdock, etcétera, sin embargo en las ciencias sociales cobra auge la utilización 
anglosajón impulsó en esos años el uso de la categoría gender, con los objetivos de diferenciar los hechos sociales y culturales de los biológicos, comprender mejor la realidad social y advertir que las características femeninas no eran adquiridas de manera natural, sino gracias a un proceso individual y social (Lamas, 2002: 87). Sin embargo, el interés en el género como categoría analítica surgió más tarde, a finales del siglo xx (Scott, 1996: 287). Es decir, de forma muy reciente. De ahí que se hable todavía de una labor por hacer en la academia, en cuanto a la demarcación, legitimación y divulgación de este tipo de estudios.

El género lo define Joan W. Scott en 1986 como "un elemento constitutivo de las relaciones sociales basadas en las diferencias que distinguen los sexos y [...] [como] una forma primaria de relaciones significantes de poder" (1996: 289). La definición de Scott, permite que hablemos de los amplios alcances que tienen los estudios de género. El feminismo propone en principio una reflexión y una crítica en todos los ámbitos (social, político, económico, etcétera) y, en lo que al rol de las mujeres se refiere, pretende visualizar y proponer una condición favorable para las mismas, equitativa y equiparable a la de los hombres; los estudios de género, además de orientarse a las mujeres, se han ido ampliando hacia otras relaciones en las que hay desigualdades de poder significativas vinculadas a los supuestos sexo/genéricos, como lo son, por ejemplo, las minorías sexuales (gays, lesbianas, bisexuales, transexuales, transgéneros y personas interesexuales) en oposición a la heterosexualidad y las formas de masculinidades disidentes en oposición a las masculinidades hegemónicas. ${ }^{6}$

de dicha categoría en los setenta, pues los estudiosos empezaron a incluir esa perspectiva de forma más seria en sus trabajos (Cf. Domenella, 2011: 30).

${ }^{6}$ Se puso en duda al feminismo hegemónico desde distintas perspectivas. Por ejemplo el hecho de que se excluyera el concepto de raza dio origen a que se empezara a teorizar en los Estados Unidos desde la comunidad afroamericana. De 
En un intento de las académicas feministas en los ochenta por legitimar sus estudios, empezaron a utilizar el término estudios de género para denominar los estudios de la mujer (Scott, 1996: 270). Debido a esto, es frecuente que al pensar en estudios de género pensemos exclusivamente en esta vertiente. Es además relevante el peso que ha tenido este eje pues, como se ve más adelante, la producción de estudios académicos de género relacionados con las mujeres es más usual que los estudios de género vinculados a otras líneas como lo son las de las minorías sexuales y las masculinidades.

Pero ¿cuál es la conexión entre los estudios de género y los estudios literarios? En cuanto a los estudios literarios, puede decirse que están incrementando cada vez más los trabajos de investigación que abordan el género o que incluyen dicha perspectiva. Pero ¿por qué? ¿Qué es lo que ha ocurrido en el campo de los estudios literarios que ha posibilitado que los trabajos se orienten al género? Y más importante aún: ¿por qué es que ahora son más comunes los cruces disciplinarios? ¿Bajo qué criterios se dan éstos?

En la introducción a La teoría literaria contemporánea de Selden, hay algunas afirmaciones que son cruciales para entender el estado actual de los estudios literarios, una es que "la 'teoría' singular y capitalizada ha evolucionado con rapidez en una serie de 'teorías' - a menudo sobrepuestas y mutuamente generativas, pero también en controversia productiva-" (2001: 19). ${ }^{7}$ Es decir, ya no se puede hablar -incluso no creemos que haya sido posible antesde que las formas de analizar los textos literarios son exclusivas y limitadas. Surgen, gracias a nuevas propuestas y desplazamientos

igual manera la exclusión de la opción sexual dio pie a que se revisara y se abordara de forma más puntual lo lésbico, gay y queer (Cf. Domenella, 2011:33). ${ }^{7}$ Nietzsche diría "la teoría ha muerto". Lacan: "la teoría no existe"; si recordamos su controversial y muchas veces malinterpretada afirmación: "La mujer no existe". 
epistemológicos, teorías y metodologías muy distintas a las tradicionales, que sin duda responden a una realidad y necesidad inmediata. De ahí que en los estudios literarios se incrementen las perspectivas a partir de las cuales se observan los textos, sobre todo los contemporáneos. De igual manera, se apunta en la misma introducción, que ha sido notable en el campo de dichos estudios la deconstrucción de las ideas de un canon literario determinado. El reto teórico de los criterios sobre los que se cimienta el canon, así como la aparición de muchos tipos de producciones literarias que se consideran marginales, han hecho que se empiece a cuestionar lo que es pertinente y digno de estudiar. La inclinación ha sido entonces desplazar los estudios literarios hacia formas de "estudios culturales", en los que se puede estudiar un repertorio más amplio e independiente de cánones (Cf. Selden, 2001: 19-20).

En este sentido, esta vertiente de los estudios literarios a través de los estudios culturales brinda la facultad de hacer investigaciones notables y serias con perspectiva de género, por ejemplo, de textos que muchas veces han sido relegados por la crítica. Así mismo nos ofrece la posibilidad no sólo de analizar las obras en un sentido formal, sino de reinterpretar el discurso literario como una forma más de representación de la cultura. ${ }^{8}$ Aunque, claro está, no debe olvidarse que al hacerse estas interconexiones disciplinarias desde los estudios literarios el centro sigue siendo la obra de ficción misma, pues finalmente es el corpus con el cual se trabaja.?

8 "Estas teorías fomentan una representación global y un cambio de frente de todas las formas de discurso como parte de una política cultural radical, en la cual 'lo literario' puede ser simplemente una forma más o menos importante de representación" (Selden, 2011:20).

${ }^{9}$ Los estudios culturales no utilizan una teoría per se, trabajan en conjunto con teorías y conceptos de distintas disciplinas del área de las humanidades o las ciencia sociales, según sea el caso, y los refuncionalizan con el objetivo de hablar de manifestaciones culturales ubicadas en una coyuntura. Stuart Hall siempre 
¿Pero cuál es la razón de estudiar la literatura a partir del género? Si bien la literatura es una construcción artística y su naturaleza se sujeta en principio a una configuración textual; como obra de arte y como texto, la literatura es un espacio de representación y de significación. Como representación del hombre, la literatura, a través del discurso y las acciones, alude directa o indirectamente a temas que abordan la condición humana. Bajtín decía, por ejemplo, que los diálogos externamente expresados en una novela representaban un fenómeno más extenso, pues éstos penetran "todo el discurso humano y todos los nexos y manifestaciones de la vida humana en general, todo aquello que posee sentido y significado" (Bajtín, 2003: 67). Es decir, pese a que no es una réplica de la realidad, como producto cultural uno puede reconocer en la literatura elementos de la realidad misma, como sentimientos, valores, roles sociales, formas de organización, etcétera. Y dentro de estos elementos, el género también está presente en la literatura como un componente de las relaciones sociales basadas en las diferencias que distinguen los sexos. ${ }^{10}$ Uno puede observar esto ya sea en la interacción entre los personajes de los mundos creados por los autores, como en la producción de la obra e incluso en la recepción de la misma.

Ahora bien, quisiéramos apuntar qué es lo que ocurre con el género y la literatura en el caso particular de México. Si bien no

dejó en claro esto, pues jamás habló de una teoría unívoca de los estudios culturales. Antes bien, se debía ubicar el estudio en el campo del saber al cual perteneciera la cuestión a tratar: "We had to respect and engage with the paradigms and traditions of knowledge and of empirical and concrete work in each of these disciplinary areas in order to construct what we called cultural studies or cultural theory" (Hall, 1990: 16).

${ }^{10}$ Judith Butler (2006) opina que el texto literario puede llegar a ser una pauta cultural que indica, por medio de la representación de la realidad, la posición que deben guardar los sexos al relacionarse entre sí. 
puede hablarse de que hay una apertura total a estudiar la literatura a partir del género por grupos conservadores, sí puede reconocerse el empeño de las cada vez más numerosas universidades e instituciones por poner en perspectiva el género; otras, incluso, exigen que los estudios literarios reconozcan la presencia del género dentro de la literatura como un elemento constitutivo de las relaciones. Dentro de estas labores tan valiosas podemos mencionar, por ejemplo: el PIEM, Programa Interdisciplinario de Estudios de la Mujer de El Colegio de México; el PuEg, Programa Universitario de Estudios de Género de la UnAm; el Centro de Investigación en Estudios de Género y Equidad de la Universidad Autónoma del Estado de México; el Centro de Estudios de Género de la Universidad de Guadalajara; el Centro de Estudios de Género de la Universidad de Colima; el Centro de Estudios de Género de la Universidad Veracruzana; el Instituto de Liderazgo Simone de Beauvoir; el Centro de Estudios de Género de la Universidad Benemérita de Puebla, que dentro de sus líneas de investigación incluye la literatura. Debe mencionarse también la labor del $\mathrm{CEIICH}$, Centro de Investigaciones Interdisciplinarias en Ciencias y Humanidades de la UNAM, que al realizar investigaciones interdisciplinarias entre las ciencias y las humanidades, le dedica especial atención al género y la literatura. ${ }^{11}$

${ }^{11}$ Instituciones o universidades que ofrecen posgrados o cursos relacionados con el género: el PIEM ofrece la Maestría en Estudios de Género; el curso de verano "Debates Contemporáneos en los Estudios de Género" del PIEM; la UAM Xochimilco ofrece la Maestría en Estudios de la Mujer; la Maestría en Estudios del Discurso de la Universidad Michoacana de San Nicolás de Hidalgo tiene la literatura de perspectiva de género como una de sus líneas de investigación; la Maestría en Estudios Interdisciplinarios de Género de la Universidad Autónoma de Ciudad Juárez; el seminario "Estudios de género" de la Facultad de Filosofía y Letras de la Universidad de Tlaxcala. Coloquios o congresos de género: el "Congreso Nacional de Estudios de Género en Humanidades: Historia, Antropología, Filosofía, Literatura y Lingüística” de la Universidad Autónoma 
Las temáticas más sobresalientes de los estudios literarios con perspectiva de género en México, según Castro Ricalde, son: la identidad femenina, que casi siempre se aborda mediante el análisis del cuerpo y la escritura; la subordinación de la mujer, sus representaciones y estereotipos; los procesos que dan un rango limitado de las imágenes femeninas, haciendo énfasis en cómo el poder permea dichas relaciones; la relectura de escritoras canónicas, visibilización de escritoras poco conocidas y estudios de escritoras a través de ángulos distintos a los acostumbrados en la academia; configuración de imágenes y representaciones de la mujer a través de los textos literarios; contrastes entre lo masculino y lo femenino; masculinidades; identidades fluctuantes; redefinición de los papeles tradicionales de género, y trabajos basados en teorías queer (Castro Ricalde, 2002: 18-19). A partir de esta lista de temáticas, pensamos que también sería relevante trabajar la recepción literaria desde el género; pudieran surgir propuestas interesantes, además se atendería uno de los elementos indispensables para que sea posible la literatura: el lector.

\section{Reflexiones finales}

A modo de cierre, no podemos pasar por alto la obviedad de que hay una exigencia, por parte de los diversos objetos de estudio, de hacer interconexiones entre disciplinas, para así fomentar análisis no sólo más profundos, sino también más críticos y comprometi-

de Tlaxcala; el "Coloquio de Investigaciones sobre Mujeres y Perspectiva de Género" de la Universidad Autónoma de Zacatecas; el "Coloquio Latinoamericano de Estudios de Género" de El Colegio de Estudios Latinoamericanos y el PUEG; el "Encuentro Intrainstitucional de Estudios de Género" de la Universidad Veracruzana; el "Congreso de Estudios de Género en el Norte de México", que organizan la UACJ, la UABC, y otras escuelas e instituciones. 
dos. En este sentido nos parecen pertinentes los viajes de conceptos de una disciplina a otra.

En cuanto al eje que ha permitido que haya interconexiones, específicamente entre los estudios culturales, los de género y los literarios, tiene que ver con que los tres comparten el hecho de estar relacionados con significaciones culturales. Es de esta manera, a través del abordaje de la cultura, que se traza un vértice que hace posibles las construcciones de sentidos, sustentadas en un marco más amplio e incluyente de teorías, conceptos y metodologías.

Consideramos también que es positivo para todas las disciplinas ser más flexibles con respecto al hecho de que puedan trabajar en conjunto con otras. Debemos intentar tener una mayor apertura con respecto a dicha cuestión; pero no en aras de, como alguna vez manifestó Jameson, "una celebración posmoderna del desdibujamiento de las fronteras" (Jameson/Zizek, 1998: 91), o de eliminar por completo la cientificidad y la formalidad de las disciplinas, sino probando alternativas que puedan brindarnos resultados más pertinentes. Claro está, e insistimos en este punto, al hacer este tipo de trabajos no debe olvidarse nunca que los estudios deben valerse, indiscutiblemente, de herramientas teóricas y metodológicas.

En el caso de los estudios literarios, estimamos que se pueden ver nutridos de manera significativa de los estudios culturales y, en especial, de los estudios de género. Mientras el centro de los análisis de las obras sigan siendo los textos mismos, pensamos que es válido que se establezcan vínculos entre las áreas mencionadas. Es importante recordar que la literatura, por un lado tiene, una naturaleza textual formal y, por otro lado, es una representación de cuestiones concernientes a la humanidad y un producto cultural.

Casi para finalizar, podemos decir que no hay consenso con respecto al tema de la vinculación entre los estudios culturales, los de género y los literarios, hay muchas opiniones al respecto, mu- 
chas escuelas, diferentes formas de asociarlos y de hacer conexiones entre estas disciplinas. Lo que es seguro es que es un asunto que no se agota aquí, queda abierto a reflexiones y discusiones futuras, pues no podemos pretender que no es notable la interdisciplina cuando en la actualidad muchos académicos están optando por la realización de estos estudios no tradicionales, simplemente como otra opción que les permite acercarse más a sus objetos de estudio para hacer análisis más finos y coyunturales.

Por último, queremos hacer énfasis que, en el caso de Latinoamérica y en especial de México, hay mucho por hacer con respecto a los estudios culturales, en el sentido de que -como estos estudios surgieron en otro país y en otro contexto- debemos seriamente replantearnos el objeto de dichos estudios situándolos en nuestro presente y realidad. Esto no significa que nos limitemos a analizar lo propiamente mexicano o latinoamericano, de ninguna manera, sino que reubiquemos los estudios culturales desde una mirada propia y atendiendo a lo inmediato. Si miramos a otras partes, podemos darnos cuenta de que las diversas escuelas de estudios literarios de cada país, o zonas geográficas, han hecho suyos los estudios culturales y les han dado un giro particular. Consideramos que en Latinoamérica y en México estamos ocupándonos de esto, sin embargo también creemos que todavía hay un largo camino por delante y que lo ideal es seguir trabajando en ello.

\section{Bibliografía}

Bajtín, Mijaíl, 2003, Problemas de la poética de Dostoievski, FCE, México.

Bal, Mieke, 2006, "Conceptos viajeros en las humanidades", Estudios visuales: Ensayo, teoría y crítica de la cultura visual y el arte contemporáneo, núm. 3, Cendeac, España, pp. 28-77. 
Braidotti, Rosi, 2000, Sujetos nómades, Paidós, México.

Buttler, Judith, 2006, Deshacer el género, Patricia Soley-Beltrán (trad.), Paidós, Barcelona.

Castro Ricalde, Maricruz, 2012, "El género, la literatura y los estudios culturales en México”, Época II, vol. XVIII, núm. 35, Colima, pp. 9-29.

Domenella, Ana Rosa, 2011, "De los estudios de género a la teoría queer: un trayecto entre cuerpos sexuados y cuerpos textuales. Una mirada desde la literatura latinoamericana", en Los prototipos de hombres y mujeres a través de los textos latinoamericanos del siglo XX, Adriana Sánez Valdez (coord.), uMSNH/UdG/UANL, México.

Grossberg, Lawrence, 2006, "Stuart Hall sobre raza y racismo: Estudios culturales y la práctica del contextualismo", en Tabula Rasa, Universidad Colegio Mayor de Cundinamarca, Colombia, núm. 5, julio-diciembre, pp. 45-65.

Hall, Stuart, 1990, "The Emergence of Cultural Studies and the Crisis of the Humanities". The Humanities as Social Technology, vol. 53, octubre, summer, pp. 11-23.

Jameson, Fredrich y Slavoj Zizek, 1998, Estudios culturales: Reflexiones sobre el multiculturalismo, Eduardo Grüner (intro.), Paidós, Argentina.

Lamas, Martha, 2002, "Usos, dificultades y posibilidades de la categoría género", en Cuerpo: Diferencia sexual y género, Aguilar, México, pp. 85-127.

Scott, Joan W., 1996, "El género una categoría útil para el análisis histórico", en El género. La construcción de la diferencia sexual, Martha Lamas (comp.), PUEG, México, pp. 265-302.

Selden, et al., 2001, La teoría literaria contemporánea, Ariel, España. 